glycaemia, and the present trial refers to patients initially treated in this way. Yet, even in these patients, when oral therapy was discontinued $31^{\circ}$, remained as well controlled as when taking their tablets. These findings suggest that even when the need for tablet therapy has been established by a poor initial response to simple dietary restriction, the introduction of tablets should not be regarded as necessarily permanent. The dose can steadily be reduced and then discontinued if normoglycaemia is maintained. When hyperglycaemia recurs it seems reasonable, in the present state of our knowledge, to reintroduce tablet therapy at the previous effective dose level. There is no firm evidence that insulin is more or less effective than oral therapy in preventing the degenerative complications in diabetics who cannot be controlled on simple dietary restriction.

\section{References}

Bloom, A. (1959). British Medical Fournal, 2, 731

Bloom, A. (1969). Postgraduate Medical fournal, Phenformin Supplement.

Bloom, A. (1969). Postgraduate Medical
British Medical fournal, 1970, 2, 443.

British Medical fournal, 1970, 2, 443.
Constam, G. R. (1971). Diabetologia, 7, 237

Constam, G. R. (1971). Diabetologia, 7, 237 . 2, 327 .

Keen, H., et al. (1965). Lancet, 2, 505.

Keen, H., and Jarrett, R. H. (1970). In Atherosclerosis: Proceedings of the Second Symposium, ed. R. J. Jones, p. 435. New York, Springer.

Lancet, 1971, 1, 171 .

Muller, R., Bauer, G., Schroder, R., and Saito, S. (1969). Hormone and Metabolism Research, 178, Suppl. No. 1, p. 88.

Passikivi, J. (1970). Acta Medica Scandinavica, Supplement No. 507.

University Group Diabetes Program (1970). Diabetes, 19, Suppl. No. 2, p. 747.

University Group Diabetes Program (1971). fournal of the American Medical Association, 217, 777.

\title{
Toxicity of Trimethoprim-Sulphamethoxazole in Patients with Megaloblastic Haemopoiesis
}

\author{
I. CHANARIN, J. M. ENGLAND
}

British Medical fournal, 1972, 1, 651-653

\begin{abstract}
Summary
Four consecutive patients with megaloblastic anaemia who also received therapy with trimethoprim-sulphamethoxazole all showed poor responses to specific haematinic therapy. This was attributed to trimethoprim, which suppressed reticulocyte responses in three cases and produced a pancytopenia in two and a falling haemoglobin with neutropenia in a third. A fourth patient, with pernicious anaemia, had a satisfactory reticulocyte response but experienced no clinical benefit until after withdrawal of trimethoprim.
\end{abstract}

Trimethoprim seems not to be a safe form of therapy in patients with a megaloblastic process; many of the toxic reactions reported with this drug may be on the basis of an unrecognized megaloblastic form of haemopoiesis.

\section{Introduction}

The trimethoprim-sulphamethoxazole drug combination has been in clinical use since 1968 and relatively few serious haematological complications associated with its administration have been recorded.

Whitman (1969) found that $1 \mathrm{~g}$ of trimethoprim daily given to healthy volunteers produced megaloblastic marrow changes in 8 out of 10 subjects. A similar dose given to 13 patients with chronic urinary trace infection produced some evidence of haematological change in 11-that is, leucopenia, thrombocytopenia, or appearance of hypersegmented neutrophils (Kahn, Fein, and Brodsky, 1968).

In the first six months after the introduction of the drug combination Hanley (1969) collected four examples of depression of leucocytes, nine of thrombocytopenia or purpura, and one report of aplastic anaemia. Allison, Kennedy, Mc-

Northwick Park Hospital and Clinical Research Centre, Harrow, Middlesex

I. CHANARIN, M.D., M.R.C.PATH., Consultant Haematologist Council
J. MAND, M.B., B.S., B.SC., Research Fellow of the Medical Research
Geachie, and McDonald (1969) did not find any appreciable blood changes in 25 women treated for seven days, although there was a significant fall in serum folate level. Hughes (1969) did not record any blood changes in 25 chronic bronchitics treated for seven days.

One patient with thrombocytopenia and megaloblastic marrow changes among 10 chronic bronchitics given $250 \mathrm{mg}$ of trimethoprim and $500 \mathrm{mg}$ of sulphamethoxazole twice daily for three months was found by Jenkins, Hughes, and Hall (1970). A further case of megaloblastic anaemia with this drug combination was reported by Jewkes, Edwards, and Grant (1970). Anaemia, neutropenia, and thombocytopenia in a puerperal woman given trimethoprim-sulphamethoxazole was reported by Mohan (1969). Other examples of neutropenia were recorded by Paulley (1970), Evans and Tell (1969), McCarthy (1969), and Hulme and Reeves (1971). Three cases of thrombocytopenia were recorded by McPherson and Raik (1970) and Hammett (1970) and a fourth patient had pancytopenia with megaloblastic marrow.

Scragg and Rubidge (1971) treated African and Indian children with typhoid fever with trimethoprim and sulphamethoxazole for 21 days. Neutropenia was noted twice as often as in a chloramphenicol-treated control group. Two children with neutropenia were also noted to have a reticulocytosis after withdrawal of therapy. Dawson and Routledge (1971) reported the appearance of a megaloblastic marrow in a woman given trimethoprim-sulphamethoxazole in whom the red cell folate level was only $16 \mathrm{ng} / \mathrm{ml}$.

Urinary tract infection is a frequent complication in women with megaloblastic anaemia, and in the past we have used trimethoprim-sulphamethoxazole as the drug of choice. The purpose of this paper is to draw attention to the toxic effects of this drug when given to patients who also have a megaloblastic process and to describe the clinical and haematological changes in four consecutive patients so treated.

\section{Case Reports}

\section{CASE 1. NUTRITIONAL VITAMIN $B_{12}$ DEFICIENCY}

The patient, a 21-year-old Indian woman from Kenya, complained of a sore tongue for four weeks. She was a strict vegetarian. The haemoglobin concentration was $6.1 \mathrm{~g} / 100 \mathrm{ml}$, total white cell 
count was $5,100 / \mathrm{mm}^{3}$ (neutrophils 2,650), and platelets were $110,000 / \mathrm{mm}^{3}$. The blood film was macrocytic with hypersegmented neutrophils and the marrow was megaloblastic. Serum vitamin $B_{12}$ level was $65 \mathrm{pg} / \mathrm{ml}$, serum folate $3 \mathrm{ng} / \mathrm{ml}$, and red cell folate $200 \mathrm{ng} / \mathrm{ml}$. The gastric juice after pentagastrin had a $\mathrm{pH}$ of 1.9 and an intrinsic factor output of 2,300 units in one hour. Faecal fat excretion, xylose excretion, and barium-meal appearances of the intestinal tract were normal. She absorbed $42 \%$ of an oral $1-\mu \mathrm{g}$ dose of ${ }^{57} \mathrm{Co}-\mathrm{B}_{12}$.

A diagnosis of nutritional vitamin $\mathbf{B}_{12}$ deficiency was made and treatment with $2 \mu \mathrm{g}$ of vitamin $B_{1: 2}$ daily by mouth was started. A routine midstream urine sample was found to contain over $10^{5}$ Escherichia coli organisms $/ \mathrm{ml}$, which were sensitive to trimethoprim-sulphamethoxazole, and treatment with this drug combination (Bactrim)-trimethoprim $320 \mathrm{mg}$ and sulphamethoxazole $1,600 \mathrm{mg}$ daily-for 10 days began on day 2 after starting oral vitamin $\mathrm{B}_{12}$.

The haematological changes are shown in Fig. 1. The reticulocytes reached $10 \%$ on day 6 after starting vitamin $B_{1}$, but thereafter they declined, and this was accompanied by a fall in the neutrophil

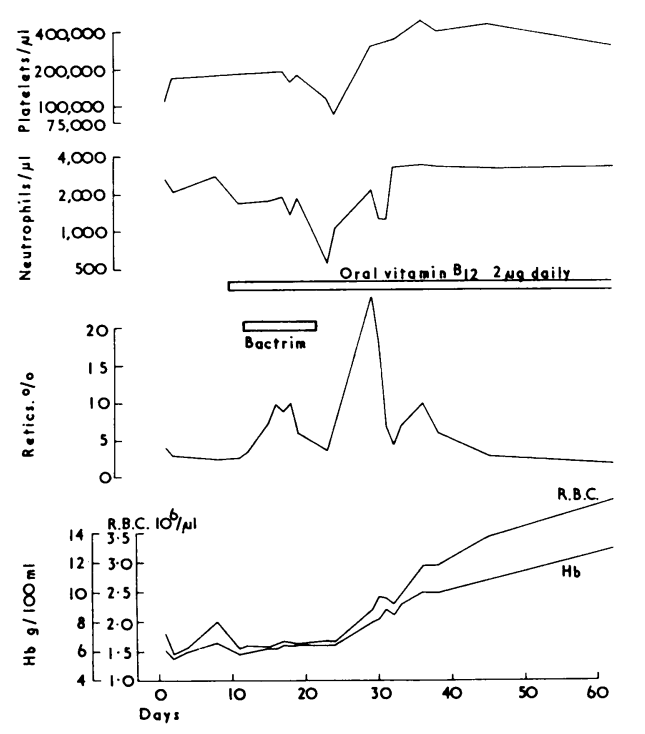

FIG. 1-Haematological changes and therapy in a patient with nutritional vitamin $B_{12}$ deficiency (Case 1).

count from 2,000 cells $/ \mathrm{mm}^{3}$ to $650 / \mathrm{mm}^{3}$ and by a fall in the platelet count from $190,000 / \mathrm{mm}^{3}$ to $85,000 / \mathrm{mm}^{3}$. There was no clinical benefit from vitamin $\mathbf{B}_{12}$ therapy and she continued to feel unwell until trimethoprim was withdrawn.

After trimethoprim was stopped there was a second reticulocytosis, reaching $24.6 \%$, and a rise in neutrophils, platelets, haemoglobin, and red cell count. This was accompanied by appreciable clinical improvement, with return of appetite and energy and disappearance of the tongue soreness.

\section{CASE 2. NUTRITIONAL FOLATE DEFICIENCY}

This 76-year-old woman was referred by her general practitioner because of persistent anaemia. There was some degree of dementia. The haemoglobin was $9 \cdot 6 \mathrm{~g} / 100 \mathrm{ml}$, white cell count was $5,600 / \mathrm{mm}^{3}$ (neutrophils 4,600 ), and platelets were $50,000 / \mathrm{mm}^{3}$. The stained blood film was macrocytic and the marrow showed megaloblastic haemopoiesis. After pentagastrin a small volume of gastric juice of $\mathrm{pH} 7.6$ was yielded, and the intrinsic factor was not measureable. The fasting serum gastrin level $(800$ units $/ \mathrm{ml})$ was raised. A provisional diagnosis of pernicious anaemia was made and treatment with intramuscular injections of vitamin $B_{1:}(2 \mu \mathrm{g}$ daily) was started. A urinary tract infection was also present, and trimethoprim $(320 \mathrm{mg}$ ) and sulphamethoxazole $(1,600 \mathrm{mg})$ daily were started on the second day after vitamin $B_{12}$.

The haematological changes are shown in Fig. 2. There was a poor reticulocyte response. The serum vitamin $B_{12}$ level $(320 \mathrm{pg} /$ $\mathrm{ml}$ ), which became available at this point, indicated that the patient did not, in fact, have vitamin $B_{12}$ deficiency. Further, the low serum folate $(1.4 \mathrm{ng} / \mathrm{ml})$ and red cell folate $(53 \mathrm{ng} / \mathrm{ml})$ indicated folate deficiency. Subsequently faecal fat excretion, xylose excretion, barium meal and follow-through examination, and a normal vitamin $\mathrm{B}_{1:}$ absorption (uptake of $61 \%$ of a $1-\mu \mathrm{g}$ dose of ${ }^{57} \mathrm{Co}-\mathrm{B}_{12}$ with normal plasma radioactivity at 10 hours) suggested a diagnosis of nutritional folate deficiency.

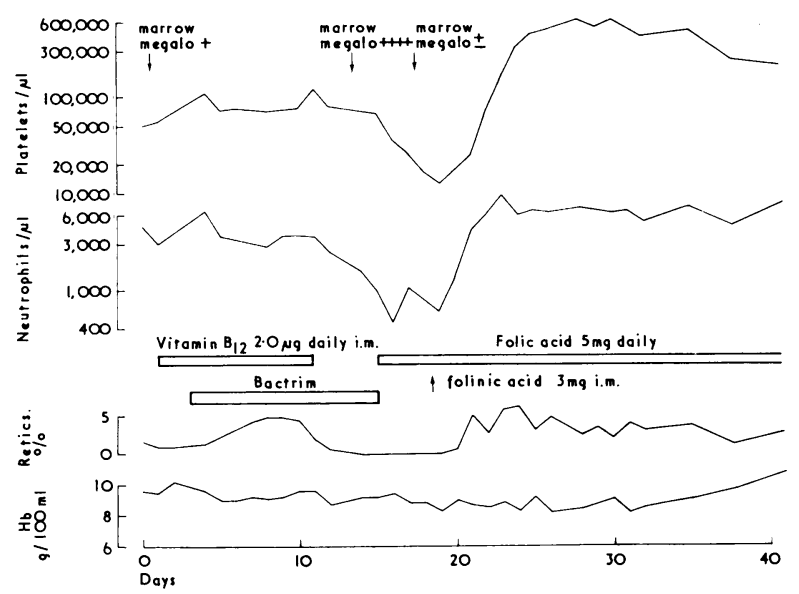

FIG. 2-Haematological changes and therapy in a patient with nutritional folate deficiency (Case 2).

Vitamin $\mathbf{B}_{1: 2}$ injections were stopped and the patient remained on Bactrim pending the completion of intestinal function studies. During this period the platelets declined to $13,000 / \mathrm{mm}^{3}$, neutrophils to $450 / \mathrm{mm}^{3}$, reticulocytes disappeared, and there was a steady fall in haemoglobin to $7.5 \mathrm{~g} / 100 \mathrm{ml}$. Purpura appeared on both legs. The marrow, which initially had shown a moderate degree of megaloblastic change, showed severe megaloblastic changes with an accumulation of basophilic and pro-megaloblasts. Large oral doses of folic acid were given ( $5 \mathrm{mg}$ daily) as well as an injection of folinic acid ( $3 \mathrm{mg}$ ) (Fig. 2). Within 48 hours of folate therapy there was a reversion of the marrow to largely normoblastic haemopoisis, and this was followed by a return of neutrophil and platelet levels to normal. There was a slower recovery of the haemogloblin level.

Assay of the leucocytes after recovery did not produce measureable levels of the enzyme dihydrofolate reductase.

\section{CASE 3. FOLATE DEFICIENCY AND RHEUMATOID ARTHRITIS}

The patient, a 56-year-old woman with an eight-year history of rheumatoid arthritis, was admitted to hospital with infected ulcers on the left leg and both feet. The E.S.R. was $143 \mathrm{~mm}$ in one hour and the latex test for rheumatoid factor was strongly positive. Although the joint manifestations appeared to be quiescent she was thought to have active vasculitis.

The haemoglobin concentration was $8.6 \mathrm{~g} / 100 \mathrm{ml}$, total white cell count was $5,500 / \mathrm{mm}^{3}$ (neutrophils 3,000 ), and platelets were $300,000 / \mathrm{mm}^{3}$. The blood film was macrocytic and the marrow showed megaloblastic haemopoiesis. There was no stainable iron in the marrow. Swabs from the leg ulcers yielded growths of Staphylococcus aureus and Streptococcus faecalis, which were sensitive to penicillin and trimethoprim. Therapy with penicillin was started. A generalized rash appeared after five days and the treatment was therefore changed to trimethoprim $(320 \mathrm{mg})$ and sulphamethoxazole $(1,600 \mathrm{mg})$.

The megaloblastic process was due to folate deficiency. The serum vitamin $B_{12}$ level was equivocal $(150 \mathrm{pg} / \mathrm{ml})$ but she absorbed vitamin $\mathrm{B}_{1: 2}$ normally $\left(74 \%\right.$ of a $1-\mu \mathrm{g}$ dose of ${ }^{57} \mathrm{Co}-\mathrm{B}_{12}$ by the faecal excretion method). The serum folate was low $(1.0 \mathrm{ng} / \mathrm{ml})$ but red cell folate was still normal $(210 \mathrm{ng} / \mathrm{ml})$. There was acid in the gastric juice ( $\mathrm{pH} 2.1$ after pentagastrin) and she secreted 680 units of intrinsic factor in an hour. Folic acid $200 \mu \mathrm{g}$ daily by mouth was started on the sixth day after the start of trimethoprim.

The haematological changes are shown in Fig. 3. There was a steady decline in haemoglobin, red cell count, platelets, and neutrophils. The response to folic acid was delayed, reticulocytes reaching $16 \%$ on the ninth day after the start of folate, and after 
trimethoprim was withdrawn a second peak of $12 \%$ occurred. Thereafter there was a rise of the red cells, platelets, and neutrophils.

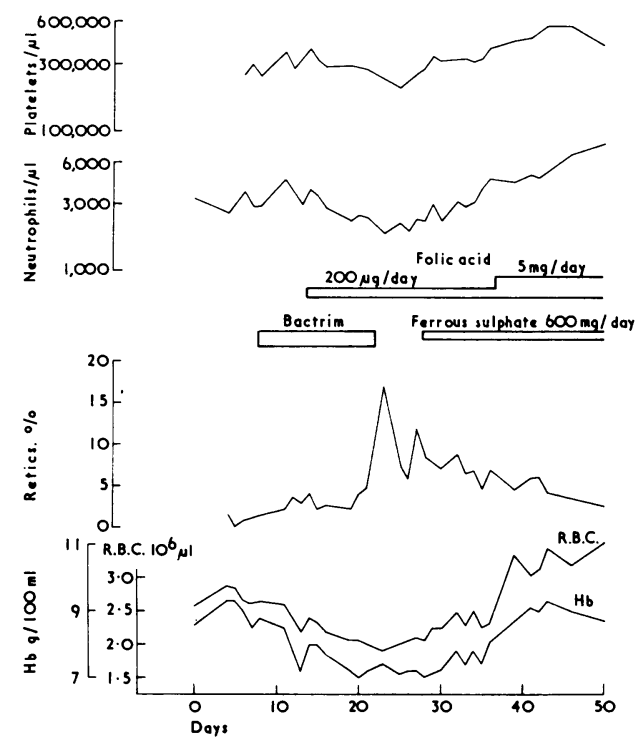

FIG. 3-Haematological changes and therapy in a patient with folate deficiency associated with rheumatoid arthritis (Case 3).

\section{CASE 4. PERNICIOUS ANAEMIA}

This 81-year-old woman was admitted to hospital with a haemoglobin concentration of $7.5 \mathrm{~g} / 100 \mathrm{ml}$ and a megaloblastic marrow. Her serum vitamin $B_{12}$ level was $60 \mathrm{pg} / \mathrm{ml}$ and she had a pentagastrin-fast achlorhydria with only 60 intrinsic factor units in the hour. Tests of vitamin $B_{1: 2}$ absorption by the urinary excretion method gave an excretion of $0.8 \%$ with the dose of vitamin $B_{12}$ alone and $24.6 \%$ when it was repeated with additional intrinsic factor.

Although there were no symptons referable to the urinary tract urine culture showed a heavy growth of $E$. coli. Treatment with trimethoprim $(320 \mathrm{mg}$ ) and sulphamethoxaole $(1,600 \mathrm{mg})$ was started three days after she had received an injection of $1,000 \mu \mathrm{g}$ of vitamin $\mathbf{B}_{12}$. The haematological response after vitamin $\mathbf{B}_{12}$ therapy appeared adequate $(21 \%$ reticulocytes on day 6 with a rise in red cell count) but she did not experience any clinical benefit - that is, there was no improvement in well-being, energy, and appetite that is normally such a characteristic feature of the response in pernicious anaemia. These features appeared only two to four days after the course of trimethoprim had terminated.

\section{Discussion}

These observations in patients with megaloblastic anaemia who were treated with trimethoprim-sulphamethoxazole show that this drug combination frequently produces a failure of haemopoiesis. In particular thrombocytopenia and neutropenia were prominent features in two of the four cases described. If given sufficiently early in relation to the haematinic substance (Case 1) it prevented the expected reticulocyte response to specific therapy. When given later (Case 4) the haematological response was adequate but there was no clinical benefit as a result of treatment.

A megaloblastic form of haemopoiesis is commonplace in clinical practice. Thus some $25 \%$ of healthy pregnant women show megaloblastic marrow changes near term (Chanarin, 1969), as do $17 \%$ of patients on anticonvulsant drugs. Minor increases in red cell volume are common when automatic blood counting machines of the Coulter $S$ type are used, and usually indicate megaloblastic marrow changes, although haemoglobin levels are often still within normal limits. Low serum folate levels are found in one-third of patients requiring hospital admission (Chanarin, 1969). Further, the frequency of pernicious anaemia in the U.K. in subjects over the age of 60 approaches $1 \%$ (Chanarin, 1969).

It seems likely that all such patients with early megaloblastic changes are at risk from trimethoprim, and the occurrence of thrombocytopenia and neutropenia in patients given this drug combination occasionally reported in the literature probably arises on the basis of a megaloblastic process.

We have no evidence that trimethoprim rather than sulphamethoxazole was responsible for the blood changes in the present patients. However, such frequent blood changes have not hitherto been seen with sulphonamides, and it seems probable that trimethoprim is the toxic agent.

Trimethoprim has a methotrexate-like effect in bacterial systems - that is, it links to the enzyme dihydrofolate reductase. The evidence that it has a similar action on the mammalian enzyme is poor, and Dr. K. Rowe in our laboratory has failed to show any effect on dihydrofolate reductase from the rat or human fetal liver. In man exposure to methotrexate leads to progressively higher dihydrofolate reductase levels in leucocytes and other tissues. It is significant that we failed to show such a rise in Case 2. Thus we feel that the mode of toxic action of trimethoprim in man is yet to be determined.

J.M.E. is supported by a Medical Research Council Fellowship. We wish to thank the sisters and staff of Haldane Ward, Roche Products Ltd., and Burroughs Wellcome \& Co. for their help.

\section{References}

Allison, M. E. M., Kennedy, A. C., McGeachie, J., and McDonald, G. A. (1969). Scottish Medical fournal, 14, 355.

Chanarin, I. (1969). Megaloblastic Anaemias. Oxford, Blackwell.

Chanarin, I. (1969). Megaloblastic Anaemias. Oxford, Blackwell.

Dawson, D. W., and Routledge, R. C. (1971). British Medical fournal, 4

Hammett, J. F. (1970). Medical fournal of Australia, 2, 200.

Hanley, T. (1969). Postgraduate Medical fournal, Suppl., vol. 45, p. 84.

Hughes, D. T. D. (1969). British Medical fournal, 4, 470.

Hulme, B., and Reeves, D. S. (1971). British Medical fournal, 3, 610.

Jenkins, G. C., Hughes, D. T. D., and Hall, P. C. (1970). fournal of Clinical Pathology, 23, 392

Jewkes, R. F., Edwards, M. S., and Grant, B. J. B. (1970). Postgraduate Medical fournal, 46, 723.

Kahn, S. B., Fein, S. A., and Brodsky, I. (1968). Clinical Pharmacology and Therapeutics, $9,550$.

McCarthy, O. R. (1969). British Medical fournal, 3, 113

McPherson, V. J., and Raik, E. (1970). Medical fournal of Australia, 2, 754.

Mohan, P. (1969). Practitioner, 202, 553 .

Maulley, J. W. (1970). British Medical fournal, 2, 364

Scragg, J. N., and Rubidge, C. J. (1971). British Medical fournal, 3, 738.

Whitman, E. N. (1969). Postgraduate Medical fournal, Suppl., vol. 45, p. 46. 